\title{
Serum Transferrin Predicts New-Onset Type 2 Diabetes in Koreans: A 4-Year Retrospective Longitudinal Study
}

\author{
Jong Dai Kim ${ }^{1}$, Dong-Mee Lim¹ ${ }^{1}$ Keun-Young Park ${ }^{1}$, Se Eun Park², Eun Jung Rhee ${ }^{2}$, Cheol-Young Park², \\ Won-Young Lee ${ }^{2}$, Ki Won $\mathrm{Oh}^{2}$ \\ ${ }^{1}$ Division of Endocrinology, Department of Internal Medicine, Konyang University Hospital, Konyang University College of \\ Medicine, Daejeon; ${ }^{2}$ Division of Endocrinology and Metabolism, Department of Internal Medicine, Kangbuk Samsung \\ Hospital, Sungkyunkwan University School of Medicine, Seoul, Korea
}

Background: It is well known that high serum ferritin, a marker of iron storage, predicts incident type 2 diabetes. Limited information is available on the association between transferrin, another marker of iron metabolism, and type 2 diabetes. Thus, we investigated the association between transferrin and incident type 2 diabetes.

Methods: Total 31,717 participants (mean age, 40.4 7.2 years) in a health screening program in 2005 were assessed via cross-sectional analysis. We included 30,699 subjects who underwent medical check-up in 2005 and 2009 and did not have type 2 diabetes at baseline in this retrospective longitudinal analysis.

Results: The serum transferrin level was higher in the type 2 diabetes group than in the non-type 2 diabetes group (58.32 \pm 7.74 $\mu \mathrm{mol} / \mathrm{L}$ vs. $56.17 \pm 7.96 \mu \mathrm{mol} / \mathrm{L}, P<0.001)$. Transferrin correlated with fasting serum glucose and glycosylated hemoglobin in the correlational analysis $(r=0.062, P<0.001$ and $r=0.077, P<0.001$, respectively) after full adjustment for covariates. Transferrin was more closely related to homeostasis model assessment of insulin resistance than to homeostasis model assessment of $\beta$ cell function ( $r=0.042, P<0.001$ and $r=-0.019, P=0.004$, respectively) after full adjustment. Transferrin predicted incident type 2 diabetes in non-type 2 diabetic subjects in a multivariate linear regression analysis; the odds ratio ( $95 \%$ confidence interval [CI]) of the 3rd tertile compared to that in the 1st tertile of transferrin for incident diabetes was 1.319 (95\% CI, 1.082 to 1.607) after full adjustment $(P=0.006)$.

Conclusion: Transferrin is positively associated with incident type 2 diabetes in Koreans.

Keywords: Transferrin; Diabetes mellitus, type 2; Insulin resistance

\section{INTRODUCTION}

Iron is a mineral that is essential for healthy body function. One of the major functions of iron is oxygen transport. Iron is also essential for hematopoiesis in the bone marrow. Iron balance is important in cell signaling and homeostasis. Iron is a strong pro-

Received: 26 May 2020, Revised: 28 July 2020, Accepted: 10 August 2020

Corresponding author: $\mathrm{Ki}-\mathrm{Won} \mathrm{Oh}$

Division of Endocrinology and Metabolism, Department of Internal Medicine, Kangbuk Samsung Hospital, Sungkyunkwan University School of Medicine, 29 Saemunan-ro, Jongno-gu, Seoul 03181, Korea

Tel: +82-2-2001-2579, Fax: +82-2-2001-2440, E-mail: okwendo@naver.com oxidant that catalyzes several cellular reactions that result in the production of reactive oxygen species (ROS); excess ROS can cause oxidative stress [1,2].

Ferritin, a protein that circulates in the blood, is an index of stored iron. In previous cross-sectional and longitudinal epidemiologic studies, a condition of iron overloading, characterized

Copyright $\odot 2020$ Korean Endocrine Society

This is an Open Access article distributed under the terms of the Creative Commons Attribution Non-Commercial License (https://creativecommons.org/ licenses/by-nc/4.0/) which permits unrestricted non-commercial use, distribution, and reproduction in any medium, provided the original work is properly cited. 
by high ferritin was correlated to many metabolic findings. For example, high serum ferritin is associated with insulin resistance, fatty liver, and metabolic syndrome $[3,4]$. Moreover, high ferritin predicts new onset type 2 diabetes (T2D) in patients without diabetes $[5,6]$. In in vivo and in vitro studies, iron also induced insulin resistance in the hepatocytes and the adipocytes. Iron status affects the insulin sensitivity by modulating the transcription and membrane expression/affinity of insulin receptor expression in the hepatocytes [7]. Iron negatively regulated adiponectin transcription via forkhead box protein O1 (FOXO1)mediated repression in adipocyte [8]. Iron excess results in oxidant stress to the beta cells and decreased insulin secretory capacity secondary to $\beta$ cell apoptosis [9].

Transferrin is another marker of iron status. Iron is transported in the blood by the serum protein transferrin that is produced in the liver. Its concentration is approximately $0.25 \mathrm{~g} / \mathrm{dL}$ in the serum and comprises $4 \%$ of serum proteins [10]. Transferrin is increased in an iron-deficient state. The blood concentrations of ferritin and transferrin are inversely correlated. In an iron-deficient state, ferritin is decreased, and transferrin is increased.

Although ferritin and transferrin have an inverse correlation, several reports paradoxically suggested that an increase in both ferritin and transferrin predicted insulin resistance and new onset T2D in non-T2D subjects in a European population [11-14]. To our knowledge, no studies have built upon these findings in other races; therefore, we investigated whether transferrin is related to the development of T2D in Korean subjects.

\section{METHODS}

\section{Study design and subjects}

The study design, anthropometric measures, and laboratory measures have been described previously [15]. In brief, this retrospective study included subjects who participated in the Kangbuk Samsung Health Study, a medical health check-up program at the Health Promotion Center of Kangbuk Samsung Hospital, Sungkyunkwan University School of Medicine, Seoul, Korea. Most of examinees were employees and family members of various industrial companies from across the country. The purpose of the medical health check-up program was to promote employee health through regular health check-ups and to enhance the early detection of existing diseases. The cost of the medical examinations is largely borne by the employers, and several examinees undergo examinations annually or biannually. In both 2005 and 2009, 32,884 participants underwent a health check-up. Among these, 153 subjects were excluded be- cause they had a malignancy at baseline. Eleven subjects were excluded because they had liver cirrhosis at baseline. One thousand and three subjects were excluded owing to missing data for iron metabolism indexes (serum iron, ferritin, or transferrin). The final cross-sectional analyses in 2005 were performed on 31,717 subjects.

Among the 31,717 subjects at baseline, 1,018 subjects had T2D. For longitudinal analysis for incident T2D, 1,018 subjects with underlying T2D at baseline were excluded. The presence of T2D was determined using self-reported questionnaires and the diagnostic criteria of the American Diabetes Association. Finally, 30,699 subjects were analyzed in a 4-year retrospective longitudinal study.

The participants provided written informed consent for the use of their health screening data for research. The design, protocol, and consent procedure of this study were reviewed and approved by the Institutional Review Board of Kangbuk Samsung Hospital (KBS12089) and were conducted as per the Helsinki Declaration of 1975. The Institutional Review Board waived the requirement for informed consent at the time the study was in its planning phase because researchers only accessed the database and did not require identification of personal information. Thus, no specific informed consent was obtained.

\section{Anthropometric and laboratory measurements}

Anthropometric and laboratory measurements have been described previously [15]. Height and weight were measured twice and then averaged. Body mass index (BMI) was calculated by dividing the weight $(\mathrm{kg})$ by the square of the height $(\mathrm{m})$. Blood pressure measurements were performed using a standardized sphygmomanometer after 5 minutes of rest. The waist circumference was measured in the standing position at the middle point between the anterior iliac crest and lower border of the rib by a single examiner.

All the subjects were examined after an overnight fast. The total white blood cell (WBC) count was assessed using an autoanalyzer (ADVIA 129, Bayer, Leverkusen, Germany). The hexokinase method was used to test the fasting serum glucose concentrations (Hitachi Modular D2400, Roche, Tokyo, Japan). Glycosylated hemoglobin (HbA1c) was measured using an immunoturbidimetric assay with a Cobra Integra 800 automatic analyzer (Roche Diagnostics, Basel, Switzerland) with reference values of $4.4 \%$ to $6.4 \%$. The methodology was aligned with the standards of the Diabetes Control and Complications Trial and National Glycohemoglobin Standardization Program. 
The intra-assay coefficient of variation was $2.3 \%$, and the interassay coefficient of variation was $2.4 \%$, both within the acceptable limits of the National Glycohemoglobin Standardization Program guidelines. Fasting insulin concentrations were determined with an electrochemiluminescence immunoassay (Hitachi Modular E170, Roche). Blood urea nitrogen, creatinine alanine aminotransferase (ALT), aspartate aminotransferase (AST), total bilirubin, albumin, gamma glutamyl-transferase (GGT), alkaline phosphatase, and uric acid were measured using ultraviolet without the P5P method (Advia 1650 Autoanalyzer, Bayer). Serum uric acid was measured using the Advia 1650 Autoanalyzer with the Fossati enzymatic reaction that used uricase with a Trinder-like endpoint. Serum creatinine was measured using the kinetic alkaline picrate (Jaffe) method. An enzymatic calorimetric test was used to measure the levels of total cholesterol and triglycerides (TG). The selective inhibition method was used to measure the level of high density lipoprotein cholesterol (HDL-C), and a homogeneous enzymatic calorimetric test was used to measure the level of low density lipoprotein cholesterol (LDL-C). High-sensitivity C-reactive protein (hsCRP) was analyzed with particle-enhanced immune-nephelometry on a BNIITM System (Dade Behring, Marburg, Germany). Serum calcium and phosphorous were measured using an automated clinical chemistry analyzer (Modular P analyzers, Roche). Serum-free levothyroxine and thyroid stimulating hormone (TSH) levels were measured using an RIA using a commercial kit (RIA-gnost ${ }^{\circledR}$ free thyroxine and hTSH, Schering-Cis Bio International, Gif-sur-Yvette, France). The serum ferritin levels were measured using an immunoradiometric assay (IRMA-mat Ferritin, DiaSorin, Stillwater, MN, USA). Transferrin was indirectly measured by checking the total iron biding capacity. Correlation between the total iron binding capacity and transferrin was very high $(r=0.94)$ [16]. Serum iron and transferrin were measured using a colorimetric method (Advia 1800, Siemens, Berlin, Germany). Inter-assay coefficients of variation were $8.0 \%$ for ferritin, $1.4 \%$ for iron, and $3.1 \%$ for transferrin. The reference range was 15 to $332 \mu \mathrm{g} / \mathrm{L}$ for ferritin, 11.64 to $31.34 \mu \mathrm{mol} / \mathrm{L}$ for iron, and 44.78 to $80.60 \mu \mathrm{mol} / \mathrm{L}$ for transferrin. The Laboratory Medicine Department at the Kangbuk Samsung Hospital in Seoul, Korea has been accredited by the Korean Society of Laboratory Medicine (KSLM) and the Korean Association of Quality Assurance for Clinical Laboratories (KAQACL). The laboratory participates in the Collage of American Pathologists (CAP) Survey Proficiency Testing.

The homeostasis model assessment of insulin resistance (HOMA-IR) and $\beta$ cell function (HOMA- $\beta$ ) was calculated with the following formula [17]: HOMA-IR=[fasting serum glucose $(\mathrm{mmol} / \mathrm{L}) \times$ fasting serum insulin $(\mathrm{mIU} / \mathrm{L})] / 22.5$. HOMA $-\beta=[20 \times$ fasting serum insulin $(\mathrm{mIU} / \mathrm{L})] /$ glucose $(\mathrm{mmol} / \mathrm{L})-3.5]$.

\section{Statistical analyses}

Continuous variables are reported as mean \pm standard deviation values. Categorical variables are expressed as percentages. To compare the differences between the subjects with and without T2D in 2005, the chi-square test or Fisher's exact test was used for nominal variables, and two-sample $t$ test or Mann-Whitney test was used for continuous variables. To assess the association between transferrin and glucose parameters (fasting serum glucose, HbA1c, HOMA-IR, and HOMA- $\beta$ ), we performed partial correlation analyses. An analysis of the relationship between variables, with incident T2D as an independent risk factor, was performed using the backward stepwise regression method of logistic regression analysis stratified as per tertiles. The odds ratios (ORs) and 95\% confidence intervals (CIs) were calculated. Statistical significance was considered when the two-tailed $P$ value was $<0.05$. Statistical analysis was performed using PASW Statistics version 21 (SPSS Inc., Chicago, IL, USA).

\section{RESULTS}

The transferrin concentration was higher in the T2D group than in the non-T2D group $(58.32 \pm 7.74 \mu \mathrm{mol} / \mathrm{L}$ vs. $56.17 \pm 7.96$ $\mu \mathrm{mol} / \mathrm{L}, P<0.001)$ in the cross-sectional analysis for the study participants in 2005 (Table 1). Although transferrin was negatively correlated with ferritin $(r=-0.272, P<0.001)$, ferritin was higher in the T2D group than in the non-T2D group $(146.09 \pm$ $116.63 \mu \mathrm{g} / \mathrm{L}$ vs. $89.59 \pm 72.96 \mu \mathrm{g} / \mathrm{L}, P<0.001$ ) (Table 1).

Serum transferrin was correlated with fasting serum glucose and HbA1c $(r=0.062, P<0.001$ and $r=0.077, P<0.001$, respectively) after adjustments for age, sex, WBC, total bilirubin, TG, HDL-C, hs-CRP, TSH, calcium, phosphorous, albumin, ALT, creatinine, uric acid, GGT, serum iron, and serum ferritin (Table 2 ). This relationship was comparable to that with ferritin that exhibited correlation values of $r=0.093(P<0.001)$ for fasting serum glucose and $r=0.059(P<0.001)$ for HbA1c. Transferrin was correlated with both HOMA-IR and HOMA- $\beta$ ( $r=0.042$, $P<0.001$ vs. $r=-0.019, P=0.004)$ after adjustments for age, sex, WBC, total bilirubin, TG, HDL-C, hs-CRP, TSH, calcium, phosphorous, albumin, ALT, creatinine, uric acid, GGT, serum iron, and serum ferritin. The correlation was stronger with HOMA-IR than with HOMA- $\beta$, implying that transferrin is as- 
Table 1. Comparison between Subjects with and without Diabetes at Baseline

\begin{tabular}{|c|c|c|c|}
\hline Variable & Without diabetes $(n=30,699)$ & With diabetes $(n=1,018)$ & $P$ value \\
\hline Age, yr & $39.3 \pm 6.7$ & $45.1 \pm 8.4$ & $<0.001$ \\
\hline Sex, male:female & $68.6: 31.1$ & $81.1: 18.9$ & $<0.001$ \\
\hline BMI, $\mathrm{kg} / \mathrm{m}^{2}$ & $23.5 \pm 3.1$ & $25.4 \pm 3.1$ & $<0.001$ \\
\hline SBP, $\mathrm{mm} \mathrm{Hg}$ & $112.5 \pm 14.1$ & $119.1 \pm 16.7$ & $<0.001$ \\
\hline DBP, $\mathrm{mm} \mathrm{Hg}$ & $74.6 \pm 9.7$ & $79.4 \pm 10.4$ & $<0.001$ \\
\hline WBC & $5,981.5 \pm 1.5$ & $6,705.6 \pm 1.6$ & $<0.001$ \\
\hline Fasting serum glucose, $\mathrm{mmol} / \mathrm{L}$ & $5.17 \pm 0.45$ & $8.09 \pm 2.38$ & $<0.001$ \\
\hline $\mathrm{HbA1c,} \mathrm{\%}$ & $5.36 \pm 0.32$ & $7.20 \pm 1.43$ & $<0.001$ \\
\hline $\mathrm{HbAlc}, \mathrm{mmol} / \mathrm{mol}$ & $35.1 \pm 0.50$ & $55.2 \pm 15.6$ & $<0.001$ \\
\hline $\mathrm{BUN}, \mathrm{mmol} / \mathrm{L}$ & $4.85 \pm 1.20$ & $5.36 \pm 1.35$ & $<0.001$ \\
\hline Creatinine, $\mathrm{mmol} / \mathrm{L}$ & $0.09 \pm 0.01$ & $0.10 \pm 0.01$ & $<0.001$ \\
\hline AST, IU/L & $23.98 \pm 11.57$ & $30.86 \pm 19.12$ & $<0.001$ \\
\hline ALT, IU/L & $26.63 \pm 20.65$ & $41.23 \pm 34.15$ & $<0.001$ \\
\hline Total bilirubin, $\mu \mathrm{mol} / \mathrm{L}$ & $17.23 \pm 16.98$ & $16.98 \pm 6.23$ & $<0.001$ \\
\hline Albumin, $\mu \mathrm{mol} / \mathrm{L}$ & $694 \pm 34$ & $702 \pm 38$ & $<0.001$ \\
\hline GGT, IU/L & $31.65 \pm 35.65$ & $58.31 \pm 61.98$ & $<0.001$ \\
\hline Alkaline phosphatase, IU/L & $61.98 \pm 16.32$ & $70.03 \pm 20.63$ & $<0.001$ \\
\hline Uric acid, $\mathrm{mmol} / \mathrm{L}$ & $0.329 \pm 0.086$ & $0.331 \pm 0.083$ & 0.711 \\
\hline Total cholesterol, $\mathrm{mmol} / \mathrm{L}$ & $4.92 \pm 0.85$ & $5.26 \pm 0.96$ & $<0.001$ \\
\hline Triglyceride, $\mathrm{mmol} / \mathrm{L}$ & $1.46 \pm 0.95$ & $2.18 \pm 1.36$ & $<0.001$ \\
\hline $\mathrm{HDL}-\mathrm{C}, \mathrm{mmol} / \mathrm{L}$ & $1.36 \pm 0.30$ & $1.25 \pm 0.26$ & $<0.001$ \\
\hline LDL-C, $\mathrm{mmol} / \mathrm{L}$ & $2.85 \pm 0.71$ & $3.02 \pm 0.81$ & $<0.001$ \\
\hline hs-CRP, mg/L & $0.20 \pm 4.39$ & $1.17 \pm 3.49$ & $<0.001$ \\
\hline Fasting insulin, $\mathrm{pmol} / \mathrm{L}$ & $61.50 \pm 24.29$ & $69.68 \pm 33.05$ & $<0.001$ \\
\hline HOMA-IR & $2.07 \pm 0.89$ & $3.63 \pm 2.07$ & $<0.001$ \\
\hline НOMА- $\beta$ & $108.1 \pm 51.0$ & $51.9 \pm 38.0$ & $<0.001$ \\
\hline Calcium, mmol/L & $2.33 \pm 0.09$ & $2.35 \pm 0.92$ & $<0.001$ \\
\hline Phosphorous, mmol/L & $1.13 \pm 0.14$ & $1.12 \pm 0.15$ & 0.259 \\
\hline $\mathrm{TSH}, \mathrm{mIU} / \mathrm{L}$ & $2.08 \pm 1.68$ & $1.89 \pm 1.15$ & 0.002 \\
\hline $\mathrm{fT} 4, \mathrm{pmol} / \mathrm{L}$ & $16.73 \pm 2.98$ & $17.04 \pm 5.54$ & 0.132 \\
\hline Ferritin, $\mu \mathrm{g} / \mathrm{L}$ & $89.59 \pm 72.96$ & $146.09 \pm 116.63$ & $<0.001$ \\
\hline Transferrin, $\mu \mathrm{mol} / \mathrm{L}$ & $56.17 \pm 7.96$ & $58.32 \pm 7.74$ & $<0.001$ \\
\hline Iron, $\mu \mathrm{mol} / \mathrm{L}$ & $21.38 \pm 8.68$ & $20.16 \pm 7.89$ & 0.672 \\
\hline
\end{tabular}

Values are expressed as mean \pm standard deviation.

BMI, body mass index; SBP, systolic blood pressure; DBP, diastolic blood pressure; WBC, white blood cell; HbA1c, glycosylated hemoglobin; BUN, blood urea nitrogen; AST, aspartate aminotransferase; ALT, alanine aminotransferase; GGT, gamma glutamyl-transferase; HDL-C, high density lipoprotein cholesterol; LDL-C, low density lipoprotein cholesterol; hs-CRP, high-sensitivity C-reactive protein; HOMA-IR, homeostasis model assessment of insulin resistance; HOMA- $\beta$, homeostasis model assessment of $\beta$ cell function; TSH, thyroid stimulating hormone; fT4, free thyroxine.

sociated with insulin resistance independently of iron metabolism and inflammation. At the 4-year follow-up, 1,108 (3.5\%) participants exhibited incident T2D. In these individuals, baseline transferrin was higher than in those who maintained a non- diabetic status $(57.53 \pm 7.77 \mu \mathrm{mol} / \mathrm{L}$ vs. $56.14 \pm 7.98 \mu \mathrm{mol} / \mathrm{L}$, $P<0.001)$. In the multivariate binary logistic regression analysis, the OR of participants in the 3rd tertile of transferrin compared to that in the 1 st tertile was 1.636 (1.379 to $1.941 ; P<$ 
Table 2. Correlational Analysis between Transferrin and Glycemic Parameters

\begin{tabular}{|c|c|c|c|c|c|c|c|c|}
\hline \multirow{2}{*}{ Variable } & \multicolumn{2}{|c|}{ Fasting serum glucose } & \multicolumn{2}{|c|}{$\mathrm{HbA} 1 \mathrm{c}$} & \multicolumn{2}{|c|}{ HOMA-IR } & \multicolumn{2}{|c|}{ НОМА- $\beta$} \\
\hline & $r$ & $P$ value & $r$ & $P$ value & $r$ & $P$ value & $r$ & $P$ value \\
\hline \multicolumn{9}{|l|}{ Unadjusted } \\
\hline Transferrin & 0.083 & $<0.001$ & 0.114 & $<0.001$ & 0.124 & $<0.001$ & 0.042 & $<0.001$ \\
\hline Ferritin & 0.207 & $<0.001$ & 0.058 & $<0.001$ & 0.197 & $<0.001$ & -0.007 & 0.198 \\
\hline \multicolumn{9}{|c|}{ After fully adjusted } \\
\hline Transferrin & 0.062 & $<0.001$ & 0.077 & $<0.001$ & 0.042 & $<0.001$ & -0.019 & 0.004 \\
\hline Ferritin & 0.093 & $<0.001$ & 0.059 & $<0.001$ & 0.046 & $<0.001$ & -0.025 & 0.000 \\
\hline
\end{tabular}

Adjusted by age, sex, body mass index, white blood cell, total bilirubin, triglycerides, high density lipoprotein cholesterol, high-sensitivity C-reactive protein, thyroid stimulating hormone, $\mathrm{Ca}_{2}^{+}$, phosphorous, albumin, alanine aminotransferase, creatinine, uric acid, gamma glutamyl-transferase, serum iron, and serum ferritin.

HbA1c, glycosylated hemoglobin; HOMA-IR, homeostasis model assessment of insulin resistance; HOMA- $\beta$, homeostasis model assessment of $\beta$ cell function.

Table 3. OR (95\% CI) of Incident Type 2 Diabetes by Tertiles of Transferrin at Baseline

\begin{tabular}{|c|c|c|c|c|c|c|c|c|}
\hline & \multicolumn{2}{|c|}{ Unadjusted Model } & \multicolumn{2}{|l|}{ Model 1} & \multicolumn{2}{|l|}{ Model 2} & \multicolumn{2}{|l|}{ Model 3} \\
\hline & OR $(95 \% \mathrm{CI})$ & $P$ value & OR $(95 \% \mathrm{CI})$ & $P$ value & OR $(95 \% \mathrm{CI})$ & $P$ value & OR $(95 \% \mathrm{CI})$ & $P$ value \\
\hline Transferrin & & 0.000 & & 0.000 & & 0.001 & & 0.013 \\
\hline 1st tertile & 1 (Reference) & & 1 (Reference) & & 1 (Reference) & & 1 (Reference) & \\
\hline 2nd tertile & $1.304(1.095-1.552)$ & 0.003 & $1.237(1.037-1.476)$ & 0.018 & $1.195(0.990-1.442)$ & 0.063 & $1.161(0.961-1.403)$ & 0.121 \\
\hline 3rd tertile & $1.636(1.379-1.941)$ & $<0.001$ & $1.500(1.259-1.787)$ & $<0.001$ & $1.424(1.505-2.127)$ & $<0.001$ & $1.319(1.082-1.607)$ & 0.006 \\
\hline Age & & & $1.055(1.046-1.064)$ & $<0.001$ & $1.025(1.015-1.035)$ & $<0.001$ & $1.026(1.015-1.036)$ & $<0.001$ \\
\hline Sex & & & $1.228(1.026-1.471)$ & 0.025 & $0.975(0.760-1.250)$ & 0.840 & $0.215(0.660-1.098)$ & 0.234 \\
\hline BMI & & & $1.211(1.184-1.238)$ & $<0.001$ & $1.117(1.089-1.145)$ & $<0.001$ & $1.094(1.065-1.123)$ & $<0.001$ \\
\hline $\mathrm{HbAlc}$ & & & & & $27.412(21.496-34.956)$ & $<0.001$ & $26.439(20.700-33.770)$ & $<0.001$ \\
\hline Ferritin & & & & & $2.420(1.838-3.186)$ & $<0.001$ & $1.782(1.407-2.259)$ & $<0.001$ \\
\hline Serum iron & & & & & $1.002(1.000-1.004)$ & 0.019 & $1.001(0.999-1.003)$ & 0.459 \\
\hline Total bilirubin & & & & & & & $1.444(1.190-1.752)$ & $<0.001$ \\
\hline Total cholesterol & & & & & & & $1.003(1.000-1.005)$ & 0.021 \\
\hline HDL-C & & & & & & & $0.984(0.976-0.992)$ & $<0.001$ \\
\hline GGT & & & & & & & $1.003(1.002-1.005)$ & $<0.001$ \\
\hline ALT & & & & & & & $1.002(0.998-1.005)$ & 0.324 \\
\hline hs-CRP & & & & & & & $0.841(1.638-1.109)$ & 0.190 \\
\hline TSH & & & & & & & $0.985(0.933-1.040)$ & 0.594 \\
\hline Uric acid & & & & & & & $1.026(0.961-1.096)$ & 0.443 \\
\hline
\end{tabular}

OR, odds ratio; CI, confidence interval; BMI, body mass index; HbA1c, glycosylated hemoglobin; HDL-C, high density lipoprotein cholesterol; GGT, gamma glutamyl-transferase; ALT, alanine aminotransferase; hs-CRP, high-sensitivity C-reactive protein; TSH, thyroid stimulating hormone.

$0.001)$ in unadjusted model and 1.319 (1.082 to $1.849 ; P=0.006)$ in the fully adjusted model (Table 3 ). Fully adjusted model included variables, such as age, sex, BMI, HbA1c, ferritin, serum iron, total bilirubin, total cholesterol, HDL-C, GGT, ALT, hsCRP, TSH, and uric acid.

\section{DISCUSSION}

In this large Korean (East Asian) cohort study, transferrin was correlated with fasting serum glucose, $\mathrm{HbAlc}$, and insulin resistance. These associations were comparable to those with ferri- 
tin. In addition, transferrin was an independent predictor for incident T2D. Although transferrin was inversely related to ferritin; both high transferrin and ferritin was an independent risk factor for incident T2D. Thus, transferrin was related to incident T2D independently from iron metabolism.

Four previous longitudinal studies demonstrated that transferrin predicts incident T2D. All these studies were conducted in European cohorts. Subjects in the first study (Data from an Epidemiological Study on the Insulin Resistance Syndrome [DESIR] study, $n=1,277$ ) were French [11], those in the second study (Cohort of Diabetes and Atherosclerosis Maastricht Study [CODAM] study, $n=509$ ) were Dutch [12], those in the third study (Cooperative Health Research in the Region of Augsburg [KORA-F4], $n=2,893)$ were German [13], and those in the fourth study (European Prospective Investigation into Cancer and Nutrition [EPIC]-InterACT, $n=15,182$ ) were European [14]. Our cohort comprised 30,084 Koreans. Thus, transferrin predicts incident T2D in Koreans as well as in Europeans.

Risk factors for T2D include non-alcoholic fatty liver disease, TSH, uric acid, bilirubin, ALT, GGT, TG, HDL-C, glucose, HbA1c, ferritin, and calcium [18-24]. Thus, we adjusted for these potentially confounding factors in this multivariate analysis. In the multivariate binary logistic regression analysis of the DESIR study, the dependent variable was not incident T2D, but the onset of impaired fasting serum glucose. They adjusted for age, sex, BMI, waist-hip ratio, CRP, fasting serum glucose, ferritin, and iron. Thus, the DESIR study did not fully adjust for risk factors for incident T2D. In the CODAM study, the estimated glomerular filtration rate was the only laboratory variable that was adjusted for incident T2D. In the KORA-F4 study, they adjusted for TG, total cholesterol/HDL-C, creatinine, GGT, urine albumin/creatinine ratio, CRP, and interleukin-18. However, this multivariate analysis model did not include TSH, bilirubin, ALT, calcium, and importantly, fasting serum glucose. In the EPIC-InterAct study, they only adjusted for hs-CRP, ALT, and GGT as the laboratory variable. They did not adjust for fasting serum glucose in the multivariate analysis model; this could have given inaccurate results. Our study offers the advantage, over previous studies, of having fully adjusted for confounding variables.

Subjects of group that developed diabetes had higher baseline age, WBC, glucose, HbA1c, total cholesterol, TG, HDL-C, LDL-C, HOMA-IR, albumin, alkaline phosphatase, AST, ALT, uric acid, GGT, ferritin, transferrin, SBP, DBP and lower HOMA- $\beta$ than subjects of group that did not. Although our study fully adjusted for confounding variables statistically, it could not exclude possibility that baseline differences in metabolic parameters caused differences in transferrin levels as a secondary outcome.

Our present findings can be partially explained by several mechanisms. Vargas et al. [25] reported that transferrin has an antagonistic effect for insulin in vivo. Moreover, recent studies have shown that transferrin induces insulin resistance in the adipocytes [26,27]. These actions may result in increased free fatty acids and may contribute to systemic insulin resistance. In addition, an in vitro study showed that transferrin decreased the binding of insulin to insulin receptors in a human colon carcinoma cell line [28]. Transferrin may directly influence insulin resistance. In an in vitro study, insulin increased the transferrin production in the hepatocytes [29]. Increased transferrin levels may cause insulin resistance. Transferrin may be a marker of insulin resistance. In an epidemiologic, prospective cohort study, transferrin predicted new-onset insulin resistance [30].

Transferrin expression in the hepatocytes is under the control of CCAAT/enhancer-binding protein- $\alpha(\mathrm{C} / \mathrm{EBP} \alpha)$ and hepatocyte nuclear factor $4 \alpha$ (HNF-4). C/EBP $\alpha$ and HNF-4 act as transcription factors by interacting with transferrin gene promoter regions called proximal region (RPI) I and PRII [31]. Both C/ $\mathrm{EBP} \alpha$ and HNF-4 are related to T2D [32-34]. C/EBP $\alpha$ and HNF may be other links between transferrin and T2D. Transferrin may be regarded as an indirect marker of $\mathrm{C} / \mathrm{EBP} \alpha$ and $\mathrm{HNF}-4$ activity. In our study, transferrin was inversely moderately correlated with ferritin $(r=0.272)$. Thus, these findings imply that iron deficiency is not a main factor in the regulation of transferrin expression.

There are certain limitations of the present study. This was an observational study; therefore, our data cannot suggest a mechanism that underlies our observations. Second, we did not perform an oral glucose tolerance test; therefore, we do not have a 120-minute oral glucose tolerance test value. However, we were able to define T2D as an HbA1c level $>6.5 \%$ and a medical history of T2D. In fact, HbA1c correlates with post-load glucose, and these measures had enough power to exclude subjects with T2D [34]. Thus, the lack of the oral tolerance test may not limit our findings. Third, we did not have information on the participants' medication history or family history of T2D. Fourth, most participants were residents of an urban community, raising the possibility of selection bias. Therefore, the present results need to be interpreted cautiously. Fifth, follow-up period for 4 years is relatively short to observe incident T2D.

The present study is meaningful because to our knowledge, this is the first study to report a relationship between transferrin 
and incident T2D in an East-Asian population. In conclusion, the transferrin was slightly higher in subjects with T2D than in those without T2D. Transferrin was weakly correlated with elevated fasting serum glucose and insulin resistance. Although transferrin is inversely related to ferritin, a risk factor for T2D, a high transferrin level predicts new onset T2D in Korean subjects without T2D, independent of other iron indexes. Further research is needed to elucidate the exact mechanism of the association of transferrin with T2D.

\section{CONFLICTS OF INTEREST}

No potential conflict of interest relevant to this article was reported.

\section{AUTHOR CONTRIBUTIONS}

Conception or design: J.D.K., K.W.O. Acquisition, analysis, or interpretation of data: J.D.K., D.M.L., K.Y.P., S.E.P., E.J.R., C.Y.P., W.Y.L., K.W.O. Drafting the work or revising: J.D.K., K.W.O. Final approval of the manuscript: J.D.K., D.M.L., K.Y.P., S.E.P., E.J.R., C.Y.P., W.Y.L., K.W.O.

\section{ORCID}

Jong Dai Kim https://orcid.org/0000-0002-2606-3646

Ki-Won Oh https://orcid.org/0000-0002-6128-7960

\section{REFERENCES}

1. Simcox JA, McClain DA. Iron and diabetes risk. Cell Metab 2013;17:329-41.

2. Puntarulo S. Iron, oxidative stress and human health. Mol Aspects Med 2005;26:299-312.

3. Wrede CE, Buettner R, Bollheimer LC, Scholmerich J, Palitzsch KD, Hellerbrand C. Association between serum ferritin and the insulin resistance syndrome in a representative population. Eur J Endocrinol 2006;154:333-40.

4. Jehn M, Clark JM, Guallar E. Serum ferritin and risk of the metabolic syndrome in U.S. adults. Diabetes Care 2004;27: 2422-8.

5. Jiang R, Manson JE, Meigs JB, Ma J, Rifai N, Hu FB. Body iron stores in relation to risk of type 2 diabetes in apparently healthy women. JAMA 2004;291:711-7.

6. Forouhi NG, Harding AH, Allison M, Sandhu MS, Welch A, Luben R, et al. Elevated serum ferritin levels predict new- onset type 2 diabetes: results from the EPIC-Norfolk prospective study. Diabetologia 2007;50:949-56.

7. Fargion S, Dongiovanni P, Guzzo A, Colombo S, Valenti L, Fracanzani AL. Iron and insulin resistance. Aliment Pharmacol Ther 2005;22 Suppl 2:61-3.

8. Gabrielsen JS, Gao Y, Simcox JA, Huang J, Thorup D, Jones D, et al. Adipocyte iron regulates adiponectin and insulin sensitivity. J Clin Invest 2012;122:3529-40.

9. Cooksey RC, Jouihan HA, Ajioka RS, Hazel MW, Jones DL, Kushner JP, et al. Oxidative stress, beta-cell apoptosis, and decreased insulin secretory capacity in mouse models of hemochromatosis. Endocrinology 2004;145:5305-12.

10. Auerbach M, Adamson JW. How we diagnose and treat iron deficiency anemia. Am J Hematol 2016;91:31-8.

11. Fumeron F, Pean F, Driss F, Balkau B, Tichet J, Marre M, et al. Ferritin and transferrin are both predictive of the onset of hyperglycemia in men and women over 3 years: the data from an epidemiological study on the Insulin Resistance Syndrome (DESIR) study. Diabetes Care 2006;29:2090-4.

12. Wlazlo N, van Greevenbroek MM, Ferreira I, Jansen EH, Feskens EJ, van der Kallen CJ, et al. Iron metabolism is prospectively associated with insulin resistance and glucose intolerance over a 7-year follow-up period: the CODAM study. Acta Diabetol 2015;52:337-48.

13. Huth C, Beuerle S, Zierer A, Heier M, Herder C, Kaiser T, et al. Biomarkers of iron metabolism are independently associated with impaired glucose metabolism and type 2 diabetes: the KORA F4 study. Eur J Endocrinol 2015;173:64353.

14. Podmore C, Meidtner K, Schulze MB, Scott RA, Ramond A, Butterworth AS, et al. Association of multiple biomarkers of iron metabolism and type 2 diabetes: the EPIC-InterAct study. Diabetes Care 2016;39:572-81.

15. Kim MK, Baek KH, Song KH, Kang MI, Choi JH, Bae JC, et al. Increased serum ferritin predicts the development of hypertension among middle-aged men. Am J Hypertens 2012; 25:492-7.

16. Gambino R, Desvarieux E, Orth M, Matan H, Ackattupathil $\mathrm{T}$, Lijoi E, et al. The relation between chemically measured total iron-binding capacity concentrations and immunologically measured transferrin concentrations in human serum. Clin Chem 1997;43:2408-12.

17. Matthews DR, Hosker JP, Rudenski AS, Naylor BA, Treacher DF, Turner RC. Homeostasis model assessment: insulin resistance and beta-cell function from fasting plasma glucose and insulin concentrations in man. Diabetologia

Copyright (C) 2020 Korean Endocrine Society 
1985;28:412-9.

18. Gronich N, Deftereos SN, Lavi I, Persidis AS, Abernethy DR, Rennert G. Hypothyroidism is a risk factor for new-onset diabetes: a cohort study. Diabetes Care 2015;38:1657-64.

19. Viazzi F, Leoncini G, Vercelli M, Deferrari G, Pontremoli R. Serum uric acid levels predict new-onset type 2 diabetes in hospitalized patients with primary hypertension: the MAGIC study. Diabetes Care 2011;34:126-8.

20. Abbasi A, Deetman PE, Corpeleijn E, Gansevoort RT, Gans RO, Hillege HL, et al. Bilirubin as a potential causal factor in type 2 diabetes risk: a Mendelian randomization study. Diabetes 2015;64:1459-69.

21. Nakanishi N, Suzuki K, Tatara K. Serum gamma-glutamyltransferase and risk of metabolic syndrome and type 2 diabetes in middle-aged Japanese men. Diabetes Care 2004;27: 1427-32.

22. Nannipieri M, Gonzales C, Baldi S, Posadas R, Williams K, Haffner SM, et al. Liver enzymes, the metabolic syndrome, and incident diabetes: the Mexico City diabetes study. Diabetes Care 2005;28:1757-62.

23. Seo MH, Bae JC, Park SE, Rhee EJ, Park CY, Oh KW, et al. Association of lipid and lipoprotein profiles with future development of type 2 diabetes in nondiabetic Korean subjects: a 4-year retrospective, longitudinal study. J Clin Endocrinol Metab 2011;96:E2050-4.

24. Becerra-Tomas N, Estruch R, Bullo M, Casas R, Diaz-Lopez A, Basora J, et al. Increased serum calcium levels and risk of type 2 diabetes in individuals at high cardiovascular risk. Diabetes Care 2014;37:3084-91.

25. Vargas L, Kawada ME, Bazaes S, Karplus PA, Faerman CH. Insulin antagonism: a novel role for human serum transferrin. Horm Metab Res 1998;30:113-7.
26. Rumberger JM, Peters T Jr, Burrington C, Green A. Transferrin and iron contribute to the lipolytic effect of serum in isolated adipocytes. Diabetes 2004;53:2535-41.

27. Green A, Basile R, Rumberger JM. Transferrin and iron induce insulin resistance of glucose transport in adipocytes. Metabolism 2006;55:1042-5.

28. Watkins LF, Lewis LR, Levine AE. Characterization of the synergistic effect of insulin and transferrin and the regulation of their receptors on a human colon carcinoma cell line. Int J Cancer 1990;45:372-5.

29. O'Riordain MG, Ross JA, Fearon KC, Maingay J, Farouk $\mathrm{M}$, Garden OJ, et al. Insulin and counterregulatory hormones influence acute-phase protein production in human hepatocytes. Am J Physiol 1995;269:E323-30.

30. Roumen C, Feskens EJ, Jansen EH, Saris WH, Blaak EE. Changes in transferrin are related to changes in insulin resistance: the SLIM study. Diabet Med 2008;25:1478-82.

31. Zakin MM. Regulation of transferrin gene expression. FASEB J 1992;6:3253-8.

32. Ganjam GK, Dimova EY, Unterman TG, Kietzmann T. FoxO1 and HNF-4 are involved in regulation of hepatic glucokinase gene expression by resveratrol. J Biol Chem 2009; 284:30783-97.

33. Qiao L, MacLean PS, You H, Schaack J, Shao J. Knocking down liver ccaat/enhancer-binding protein alpha by adenovirus-transduced silent interfering ribonucleic acid improves hepatic gluconeogenesis and lipid homeostasis in $\mathrm{db} / \mathrm{db}$ mice. Endocrinology 2006;147:3060-9.

34. Alqahtani N, Khan WA, Alhumaidi MH, Ahmed YA. Use of glycated hemoglobin in the diagnosis of diabetes mellitus and pre-diabetes and role of fasting plasma glucose, oral glucose tolerance test. Int J Prev Med 2013;4:1025-9. 